\title{
DAMPAK SIKAP IBU TERHADAP KEBERHASILAN PEMBERIAN ASI EKSKLUSIF DI KECAMATAN ILIR TIMUR II PALEMBANG
}

\author{
${ }^{1}$ Hasna Mujahidah, ${ }^{2}$ Ardesy Melizah Kurniati, ${ }^{3}$ Asmarani Ma'mun \\ 1,2,3 Program Studi Pendidikan Dokter Fakultas Kedokteran Universitas Sriwijaya \\ Email: ${ }^{2}$ ardesy.gizi@fk.unsri.ac.id
}

\begin{abstract}
Abstrak
Cakupan pemberian air susu ibu (ASI) eksklusif di Indonesia belum maksimal. Banyak faktor yang dapat mempengaruhi ibu dalam pemberian ASI eksklusif, salah satunya adalah sikap ibu. kualitas dan kuantitas ASI. Tujuan penelitian ini adalah mengetahui hubungan sikap ibu mengenai kualitas dan kuantitas ASI dengan pemberian ASI eksklusif di Kecamatan Ilir Timur II Palembang. Penelitian ini merupakan penelitian observasional analitik dengan desain cross sectional. Sebanyak seratus orang ibu yang memenuhi kriteria berpartisipasi dalam penelitian ini. Pengambilan data dilakukan menggunakan kuesioner. Hasil data yang diperoleh dianalisis dengan uji statistik Chi-Square. Hasil penelitian menunjukkan angka keberhasilan pemberian ASI eksklusif sebesar $43 \%$. Sebagian besar ibu menunjukkan sikap yang positif terhadap kualitas dan kuantitas ASI. Sikap ibu terhadap kualitas ASI $(\mathrm{p}=0,006)$ dan kuantitas ASI $(\mathrm{p}=0,006)$ menunjukkan hubungan yang bermakna dengan pemberian ASI eksklusif. Sikap ibu di Kecamatan Ilir Timur II Palembang mengenai kualitas ASI dan kuantitas ASI berdampak signifikan terhadap keberhasilan pemberian ASI eksklusif.
\end{abstract}

Kata Kunci: ASI Eksklusif, Chi-Square, Sikap Ibu, Palembang

\section{Pendahuluan}

Air Susu Ibu (ASI) adalah cairan tubuh yang mengandung beragam nutrisi dan dihasilkan dari sekresi kelenjar payudara ibu. Kandungan zat gizi makro dan mikro dalam ASI dapat memenuhi kebutuhan bayi sesuai dengan usianya. ${ }^{1,2}$ Pemberian ASI tanpa diberi makanan tambahan apapun untuk bayi berusia 0-6 bulan disebut ASI eksklusif. World Health Organization (WHO) telah merekomendasikan pemberian ASI eksklusif hingga usia 4-6 bulan. ${ }^{3}$

Cakupan ASI ekslusif Indonesia pada tahun 2013 sebesar 54,3\% dan Sumatera Selatan termasuk provinsi dengan cakupan di atas rata-rata nasional ${ }^{4}$ Berdasarkan data Dinas Kesehatan Provinsi
Sumsel tahun 2014, cakupan pemberian ASI eksklusif pada bayi 0-6 bulan sebesar 63,44\%.5 Data Dinas Kesehatan Kota Palembang pada tahun 2015 menunjukkan cakupan pemberian ASI eksklusif sebesar $72,91 \%$, namun mengalami penurunan dari tahun sebelumnya dengan cakupan $78,3 \%$. Kecamatan Ilir Timur II Palembang memiliki cakupan yang rendah, di bawah cakupan provinsi. ${ }^{6}$

Faktor-faktor yang memengaruhi keberhasilan pemberian ASI eksklusif antara lain adanya permasalahan dalam proses menyusui, kunjungan ke klinik laktasi, keinginan ibu, keyakinan ibu, persepsi ibu tentang kepuasan bayi saat menyusu, dukungan suami, dukungan orangtua, usia ibu, pekerjaan ibu, 
pemberian susu formula di instansi pelayanan kesehatan, MPASI dini, dan pemakaian empeng. Persepsi ibu yang kuat tentang kepuasan bayi saat menyusui merupakan faktor determinan positif yang paling menentukan keberhasilan pemberian ASI eksklusif. ${ }^{7}$ Pada ibu yang telah menjalani inisiasi menyusui dini (IMD), faktor psikis ibu berupa keyakinan ibu terhadap kecukupan produksi ASI merupakan salah satu faktor yang memengaruhi pemberian ASI eksklusif. ${ }^{8}$ Pada ibu bekerja, sikap ibu yang mendukung pemberian ASI eksklusif juga merupakan faktor yang memengaruhi pemberian ASI eksklusif. ${ }^{9}$ Keluhan ketidakcukupan jumlah ASI maupun nutrisi dari ASI merupakan alasan yang umum ibu berhenti menyusui. ${ }^{1}$

Kualitas dan kuantitas ASI dapat diukur secara objektif dengan memantau pertumbuhan dan perkembangan bayi secara klinis, maupun memeriksa kadar nutrisi ASI secara laboratoris. ${ }^{2}$ Sikap ibu secara subjektif dapat memengaruhi keputusan mempertahankan pemberian ASI bahkan sebelum dilakukan pemeriksaan secara objektif. Penelitian ini dilakukan di Puskesmas kecamatan Ilir Timur II Palembang, dengan tujuan untuk mengetahui adakah hubungan antara faktor sikap ibu dengan keberhasilan pemberian ASI eksklusif.

\section{Bahan dan Metode}

Penelitian ini menggunakan metode analitik observasional dengan desain penelitian cross sectional di Kecamatan Ilir Timur II Palembang. Kriteria penelitian adalah Ibu yang memiliki anak usia 6-24 bulan yang terdaftar di lima Puskesmas wilayah kerja Kecamatan Ilir Timur II, dapat ditemui saat pengambilan data, tidak ada riwayat pemberian makanan pralakteal pada bayi, dan ibu bersedia menandatangani lembar persetujuan subjek penelitian.

Sebanyak seratus orang ibu memenuhi kriteria untuk berpartisipasi dalam penelitian ini. Subjek penelitian kemudian diwawancarai untuk mendapatkan data karakteristik, riwayat pemberian ASI eksklusif, serta sikap ibu menggunakan kuesioner berisi pernyataan mitos yang banyak beredar tentang kualitas dan kuantitas ASI (masing-masing delapan pernyataan). ${ }^{1,8,10}$ Bila ibu tidak menyetujui pernyataan tersebut, maka ibu memiliki keyakinan yang baik dan dapat mendukung keberlangsungan pemberian ASI ekslusif dan diberikan skor 1 . Total skor $>4$ dari 8 pertanyaan dinyatakan sebagai sikap positif. Analisis bivariat antara sikap ibu dan keberhasilan pemberian ASI eksklusif diuji dengan Chi-Square. Penelitian ini telah disetujui oleh Komite Etik Fakultas Kedokteran Universitas Sriwijaya-RSMH No. 438/keprsmhfkunsri/2016. 


\section{Hasil Penelitian}

Penelitian dilakukan di Puskesmas 5

Ilir, 11 Ilir, Sabokingking, Boom Baru dan Kenten yang merupakan Puskesmas di wilayah Ilir Timur 2 Palembang. Distribusi karakteristik subjek dapat dilihat pada Tabel 1. Sebagian besar subjek berada dalam usia reproduktif, cenderung berpendidikan tinggi, multipara, dan melakukan persalinan di fasilitas kesehatan dengan rawat gabung. Seluruh subjek pernah melakukan antenatal care (ANC). Sebagian kecil subjek penelitian bekerja, diantaranya sebagai bidan, guru, karyawan pemerintah maupun swasta, dan pedagang.

Tabel 1. Distribusi subjek berdasarkan usia, pekerjaan, pendidikan, ANC, jumlah paritas, rawat gabung, penolong persalinan, dan tempat persalinan $(\mathrm{N}=100)$

\begin{tabular}{|c|c|}
\hline Karakteristik Ibu & $\mathrm{n}(\%)$ \\
\hline \multicolumn{2}{|l|}{ Usia } \\
\hline $20-35$ tahun & $79(79)$ \\
\hline$<20$ tahun dan $>35$ tahun & $21(21)$ \\
\hline \multicolumn{2}{|l|}{ Pekerjaan } \\
\hline Tidak bekerja & $80(80)$ \\
\hline Bekerja & $20(20)$ \\
\hline \multicolumn{2}{|l|}{ Pendidikan } \\
\hline Tamat SD & $12(12)$ \\
\hline Tamat SMP & $15(15)$ \\
\hline Tamat SMA & $56(56)$ \\
\hline Tamat perguruan tinggi & $17(17)$ \\
\hline \multicolumn{2}{|l|}{ ANC } \\
\hline $\mathrm{Ya}$ & $100(100)$ \\
\hline Tidak & $0(0)$ \\
\hline \multicolumn{2}{|l|}{ Jumlah paritas } \\
\hline 1 kali & $24(24)$ \\
\hline$>1$ kali & $76(76)$ \\
\hline \multicolumn{2}{|l|}{ Rawat gabung } \\
\hline $\mathrm{Ya}$ & $83(83)$ \\
\hline Tidak & $17(17)$ \\
\hline \multicolumn{2}{|l|}{ Penolong persalinan } \\
\hline Bidan & $59(59)$ \\
\hline Dokter (umum/spesialis) & $41(41)$ \\
\hline
\end{tabular}

$\begin{array}{lc}\text { Tempat persalinan } & \\ \text { Rumah } & 4(4) \\ \text { Klinik } & 47(47) \\ \text { Rumah sakit } & 49(49)\end{array}$

Sebanyak 43 orang (43\%) subjek penelitian menyusui secara eksklusif. Sebagian besar ibu memiliki sikap yang negatif terhadap kualitas ASI (63\%) dan kuantitas ASI (52\%).

Tabel 2. Distribusi subjek berdasarkan pemberian ASI eksklusif dan sikap ibu $(\mathrm{N}=100)$

\begin{tabular}{lll}
\hline Distribusi & $\mathrm{n}$ & $\%$ \\
\hline Pemberian ASI eksklusif & & \\
Ya & 43 & 43 \\
Tidak & 57 & 57 \\
$\begin{array}{l}\text { Sikap ibu } \\
\text { kualitas ASI }\end{array}$ & & \\
$\quad$ Positif & 37 & 37 \\
Negatif & 63 & 63 \\
$\begin{array}{l}\text { Sikap ibu } \\
\text { kuantitas ASI }\end{array}$ & terhadap & \\
Positif & 48 & 48 \\
Negatif & 52 & 52 \\
\hline
\end{tabular}
jumlah ibu yang memiliki sikap negatif dan positif berdasarkan butir pernyataan pada kuesioner.

Hasil analisis bivariat data sikap ibu mengenai kualitas dan kuantitas ASI dengan pemberian ASI eksklusif dapat dilihat pada Tabel 4. Terdapat hubungan yang bermakna antara sikap ibu mengenai kualitas ASI maupun kuantitas ASI dengan pemberian ASI eksklusif pada subjek penelitian.

Tabel 3. Distribusi dikap ibu berdasarkan tiap butir pernyataan kuesioner $(\mathrm{N}=100)$ 


\begin{tabular}{|c|c|c|}
\hline Pernyataan kualitas ASI & Setuju & $\begin{array}{l}\text { Tidak } \\
\text { setuju }\end{array}$ \\
\hline 1. ASI bisa digantikan zat gizinya oleh susu formula. & 22 & 78 \\
\hline $\begin{array}{l}\text { 2. Susu formula lebih bagus gizinya daripada ASI sehingga bayi susu formula } \\
\text { lebih gemuk. }\end{array}$ & 22 & 78 \\
\hline $\begin{array}{l}\text { 3. Bayi yang mendapat ASI harus diberikan juga susu formula agar kebutuhan } \\
\text { gizinya tercukupi. }\end{array}$ & 73 & 27 \\
\hline $\begin{array}{l}\text { 4. Bila ibu sakit ringan (misalnya flu disertai demam), pemberian ASI dapat } \\
\text { menularkan penyakit ke bayi. }\end{array}$ & 58 & 42 \\
\hline $\begin{array}{l}\text { 5. Payudara kanan dan kiri kandungan ASI-nya berbeda, salah satunya encer } \\
\text { dan yang lain kental, sehingga kualitasnya berbeda. }\end{array}$ & 71 & 29 \\
\hline 6. Bila ibu berpuasa maka ASI-nya tidak ada gizinya. & 39 & 61 \\
\hline $\begin{array}{l}\text { 7. Ibu yang bertubuh kurus, ASI-nya kurang bergizi dibanding ibu yang } \\
\text { bertubuh gemuk. }\end{array}$ & 23 & 77 \\
\hline $\begin{array}{l}\text { 8. Bila ibu bepergian meninggalkan bayi dan payudara terasa sangat penuh, } \\
\text { sebagian ASI harus dikeluarkan terlebih dahulu sebelum payudara disusukan } \\
\text { ke bayi supaya bayi tidak sakit. }\end{array}$ & 33 & 67 \\
\hline Pernyataan kuantitas ASI & Setuju & $\begin{array}{l}\text { Tidak } \\
\text { setuju }\end{array}$ \\
\hline $\begin{array}{l}\text { 1. Produksi ASI seorang ibu menyusui pada enam bulan pertama tidak mencukupi } \\
\text { kebutuhan bayinya. }\end{array}$ & 69 & 31 \\
\hline 2. Produksi ASI semakin berkurang seiring bertambahnya usia bayi. & 63 & 37 \\
\hline 3. Ibu menyusui harus mempunyai pantangan makanan tertentu selama menyusui. & 56 & 44 \\
\hline 4. Bila bayi tetap rewel setelah disusui, artinya ASI ibu tidak cukup. & 38 & 62 \\
\hline $\begin{array}{l}\text { 5. Bayi yang sering minta disusui menandakan ASI ibu kurang banyak } \\
\text { produksinya. }\end{array}$ & 62 & 38 \\
\hline 6. Ibu dengan payudara kecil memiliki jumlah ASI yang sedikit. & 27 & 73 \\
\hline $\begin{array}{l}\text { 7. Payudara yang lembek menggambarkan ASI sudah habis dan tidak bisa dihisap } \\
\text { bayi lagi. }\end{array}$ & 52 & 48 \\
\hline 8. Produksi ASI akan semakin berkurang seiring bertambahnya anak. & 37 & 63 \\
\hline
\end{tabular}

Tabel 4. Hubungan sikap ibu mengenai kualitas dan kuantitas ibu terhadap pemberian ASI eksklusif

\begin{tabular}{clll}
\hline Sikap Ibu & \multicolumn{2}{l}{ Pemberian ASI eksklusif } & $\mathrm{p}$ \\
\cline { 2 - 3 } & $\begin{array}{l}\text { Ya } \\
\mathrm{n}(\%)\end{array}$ & $\begin{array}{l}\text { Tidak } \\
\mathrm{n}(\%)\end{array}$ & \multirow{2}{*}{0,006} \\
\hline $\begin{array}{c}\text { Sikap ibu terhadap kualitas ASI } \\
\text { Positif }\end{array}$ & $23(53,5)$ & $14(24,6)$ & \\
$\begin{array}{c}\text { Negatif } \\
\text { Sikap ibu terhadap kuantitas ASI }\end{array}$ & $20(46,5)$ & $43(75,4)$ & 0,006 \\
$\begin{array}{l}\text { Positif } \\
\text { Negatif }\end{array}$ & $28(65,1)$ & $20(35,1)$ & \\
\hline
\end{tabular}

\section{Pembahasan}

\section{Cakupan pemberian ASI eksklusif} yang didapatkan dari hasil penelitian ini menurun jauh dari rata-rata cakupan kota Palembang tahun 2015. ${ }^{6}$ Hasil ini sejalan dengan penelitian Wahyuni dan Madari ${ }^{11} \mathrm{di}$
Puskesmas Makrayu Palembang yang mendapatkan angka pemberian ASI eksklusif sebesar $40 \%$. Jumlah ini tidak jauh berbeda dengan penelitian Kurniawan ${ }^{7}$ di Lamongan dan Yuliarti ${ }^{12}$ di Tanggerang 
yang mendapatkan besar cakupan $35,3 \%$ dan $31,1 \%$.

Sebagian besar subjek penelitian menunjukkan sikap negatif terhadap kualitas dan kuantitas ASI, dan pada penelitian ini sikap tersebut ternyata berhubungan dengan perilaku pemberian ASI. Penelitian terdahulu lebih banyak menghubungkan antara sikap ibu mengenai pemberian ASI secara umum dengan pemberian ASI eksklusif dan tidak spesifik membahas sikap mengenai kualitas dan kuantitas ASI. Keluhan ibu yang merasa tidak memiliki cukup ASI dan merasa bayinya tidak mendapatkan cukup gizi dari ASI sehingga berat badannya tidak naik sesuai yang diharapkan merupakan alasan yang umum diberikan oleh para ibu, sehingga memutuskan berhenti menyusui pada minggu ketiga sejak kelahiran bayi. ${ }^{1}$ Menurut Kurniawan ${ }^{7}$, persepsi ibu yang kuat tentang kepuasan bayi saat menyusui merupakan faktor determinan positif yang paling menentukan keberhasilan pemberian ASI eksklusif. Penelitian Fahriani dkk. pada ibu yang telah menjalani inisiasi menyusui dini (IMD) menunjukkan bahwa faktor psikis ibu berupa keyakinan ibu terhadap kecukupan produksi ASI merupakan salah satu faktor yang memengaruhi pemberian ASI eksklusif. ${ }^{8}$ Pada penelitian Abdullah dkk. ${ }^{9}$ dengan subjek ibu bekerja, sikap ibu yang mendukung pemberian ASI eksklusif merupakan faktor yang mendominasi keberhasilan pemberian ASI eksklusif.

Bila dilihat berdasarkan butir pernyataan pada penelitian ini, terdapat keraguan subjek mengenai apakah jumlah ASI ibu pasti akan mencukupi kebutuhan anaknya (pernyataan tentang kuantitas ASI nomor $1,2,3,5,7)$. Terdapat keraguan pada kualitas gizi ASI (pernyatan kualitas ASI nomor 3 dan 5), meskipun pada butir pernyataan sebelumnya, sebagian besar meyakini bahwa zat gizi dalam ASI tidak tergantikan. Dalam hal ini, diduga pemberian susu formula hanya bersifat "menambal", tanpa bermaksud menggantikan, terutama pada keadaan yang dianggap darurat seperti ibu sakit (butir pernyataan kualitas ASI nomor 4). Alasan ibu yang menyatakan ASI tidak mencukupi kebutuhan bayinya juga menjadi salah satu dari tiga alasan terbanyak ibu berhenti menyusui menurut penelitian $\mathrm{Li}$ dkk. ${ }^{13}$ Menurut Prabasiwi dkk. ${ }^{14}$ yang meneliti tentang persepsi ketidakcukupan ASI, pengetahuan ibu sangat memengaruhi perasaan ibu bahwa ASI tidak mencukupi kebutuhan bayi.

Penelitian ini hanya meneliti salah satu faktor yang dapat mempengaruhi pemberian ASI eksklusif. Penelitian mengenai faktor ibu yang lain seperti psikis ibu, permasalahan menyusui yang dialami ibu, dan pengetahuan ibu dapat dilakukan 
lebih lanjut untuk mengetahui pengaruhnya terhadap sikap ibu.

\section{Simpulan}

Sikap ibu berdampak terhadap keberhasilan pemberian ASI eksklusif pada ibu menyusui di Kecamatan Ilir Timur 2 Palembang. Edukasi yang memadai sebaiknya diberikan kepada ibu, agar ibu dapat memiliki sikap positif dan berhasil memberikan ASI eksklusif kepada bayi.

\section{Daftar Pustaka}

1. Lawrence RA. Breastfeeding: a guide for the medical profession. Maryland Heights: Mosby/Elsevier; 2011. 98146.

2. Kurniati AM, Sungkar A, Sunardi D. Kadar lemak ASI matur pada ibu menyusui usia reproduktif. Jurnal Perinasia Edisi Konas XII. 2016 Jan: 19-23.

3. World Health Organization.Infant and young child feeding: model chapter for textbooks for medical students and allied health professionals.Geneva: World Health Organization; 2009.

4. Pusat Data dan Informasi Kesehatan RI. Kondisi pencapaian program kesehatan anak Indonesia. Jakarta: Kemenkes RI; 2014.

5. Dinas Kesehatan Provinsi Sumsel. Profil kesehatan Provinsi Sumatera
Selatan 2014. Palembang: Dinkes Provinsi Sumsel; 2015.

6. Dinas Kesehatan Kota Palembang. Profil Kesehatan Kota Palembang 2015. Palembang: Dinkes Kota Palembang; 2015.

7. Kurniawan B. Determinan keberhasilan pemberian air susu ibu eksklusif. Jurnal Kedokteran Brawijaya. 2013 Ags; 27(4): 236-40.

8. Fahriani R, Rohsiswatmo R, Hendarto A. Faktor yang memengaruhi pemberian ASI eksklusif pada bayi cukup bulan yang dilakukani Inisiasi menyusui dini (IMD). Sari Pediatri. 2014 Apr; 15(6): 394-402.

9. Abdullah G I, Ayubi D. Determinan perilaku pemberian ASI eksklusif pada ibu pekerja. Kesmas, Jurnal Kesehatan Masyarakat Nasional. 2013 Feb; 7(7): 298-303.

10. Rahmi N, Annisah. Faktor-Faktor yang Berhubungan dengan MitosMitos dalam Pemberian ASI Eksklusif di Wilayah Kerja Pukesmas Baiturrahman Banda Aceh. Journal of Healthcare Technology and Medicine Vol. 3 No. 1 April 2017: 42-48.

11. Wahyuni D, Madari M. Faktor-faktor yang berhubungan dengan perilaku ibu dalam pemberian ASI eksklusif di Puskesmas Makrayu Palembang. 
Jurnal Kesehatan Bina Husada. 2014 Jun; 10(1): 114-117.

12. Yuliarti ID. Hubungan Pengetahuan dan Sikap Ibu dengan Perilaku Pemberian ASI Eksklusif [tesis]. Surakarta: Fakultas Kedokteran Universitas Sebelas Maret, 2008

13. Li R, Fein SB, Chen J, GrummerStrawn LM. Why mothers stop breastfeeding: mother's self- reported reasons for stopping during the first year. Pediatrics. 2008 Okt; 122(S2): S69- S76.

14. Prabasiwi A, Fikawati S, Syafiq A. ASI eksklusif dan persepsi ketidakcukupan ASI. Kesmas, Jurnal Kesehatan Masyarakat Nasional. 2015 Feb; 9(3): 282-287. 